\title{
Molecular typing of nasal carriage isolates of Staphylococcus aureus from an Irish university student population based on toxin gene PCR, agr locus types and multiple locus, variable number tandem repeat analysis

\author{
Mark M. Collery, ${ }^{1}$ Davida S. Smyth, ${ }^{1} \dagger$ Jane M. Twohig, ${ }^{1}$ Anna C. Shore, ${ }^{2}$
} David C. Coleman ${ }^{2}$ and Cyril J. Smyth ${ }^{1}$ \\ Correspondence \\ Cyril J. Smyth \\ csmyth@tcd.ie \\ Received 30 October 2007 \\ Accepted 27 November 2007

\author{
${ }^{1}$ Department of Microbiology, Moyne Institute of Preventive Medicine, Trinity College Dublin, \\ University of Dublin, Dublin 2, Republic of Ireland \\ ${ }^{2}$ Microbiology Research Unit, Division of Oral Biosciences, Dublin Dental School and Hospital, \\ Trinity College Dublin, University of Dublin, Dublin 2, Republic of Ireland
}

\begin{abstract}
Forty-eight Staphylococcus aureus isolates collected from a young, healthy, Irish university student population from 1995 to 2004 were screened for 16 enterotoxin (SE) and enterotoxin-like (SEI) genes (sea-see, seg-sei, selj-selo, selq, selu), and for the toxic shock toxin syndrome toxin-1 gene, tst. All of the isolates harboured at least one SE or SEl gene and $66.7 \%$ possessed a classical SE gene (sea, seb, sec), the commonest being the seb gene. Most of the isolates (85.4\%) had a complete egc locus (selo, selm, sei, seln, seg). The intergenic sei-seln region of the egc locus was typed by PCR-RFLP in 34 isolates, 15 possessing pseudogenes $\psi$ ent 1 and

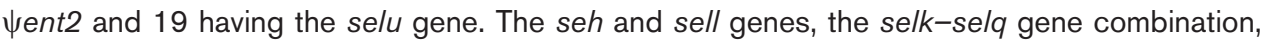
and the tst gene were each found in $<15 \%$ of isolates. The agr genotype distribution was agr type III, 37.5\%; agr type I, 35.4\%; agr type II, $25 \%$; and agr type IV, $2.1 \%$. There was no association between SE-SEl genotype and agr type. All tst gene-positive isolates were of agr type III and harboured a classical SE gene. Multiple locus, variable number tandem repeat analysis (MLVA) produced 47 different patterns. While the $s d r$ locus was present in all isolates, half of them lacked one or two of the sdr gene amplimers. Twenty isolates harboured the bbp gene, its presence being associated with agr type III, but not with the SE-SEl gene profile. The agr types of isolates were associated with MLVA subclusters. Selective MLST analysis revealed seven novel sequence types and a new aroE allele. Five clonal clusters (CCs), including CCs comprising major pandemic clones CC30, CC5 and CC22 and minor lineages CC6 and CC9, and three singletons were identified.
\end{abstract}

\section{INTRODUCTION}

Staphylococcus aureus is an opportunistic pathogen that can persist in the anterior nares of healthy human carriers (Kluytmans et al., 1997; Peacock et al., 2001; Nouwen et al., 2004; Wertheim et al., 2005). The diseases caused by $S$. aureus range in severity from superficial skin infections and food poisoning to life-threatening conditions such as toxic

tPresent address: New York Medical College, Department of Microbiology and Immunology, Valhalla, NY 10595, USA.

Abbreviations: CC, clonal cluster; MLVA, multiple locus, variable number tandem repeat analysis; PFGE, pulsed-field gel electrophoresis; SE, staphylococcal enterotoxin; SEl, staphylococcal enterotoxin-like; slv, single locus variant; ST, sequence type; TSST-1, toxic shock syndrome toxin-1. shock syndrome and septicaemia (Ferry et al., 2005; Murray, 2005; Todd, 2005).

Many molecular methods have been employed to type, differentiate, and group isolates of $S$. aureus (Shopsin \& Kreiswirth, 2001; Trindade et al., 2003; Robinson \& Enright, 2004; Vivoni \& Moreira, 2005). While currently pulsed-field gel electrophoresis (PFGE), usually with SmaIgenerated genomic DNA fragments, is considered the 'gold' standard method, it is time-consuming, requires specific and expensive equipment, and is relatively labour intensive (Arshad et al., 1993; Wagner \& Lai, 1994). In contrast, PCR-based techniques are simple to perform. Multiple locus, variable number tandem repeat analysis (MLVA) has been used to type $S$. aureus utilizing multiplex PCRs that target intragenic regions with variable numbers of tandem 
repeats, namely $c l f A, c l f B, s d r C, s d r D, s d r E, s s p A, s p a, m e c A$, fnbA, fnbB and cna (Sabat et al., 2003, 2006; Francois et al., 2005; Lindstedt, 2005; Malachowa et al., 2005). This method has been shown to have a high level of interlaboratory reproducibility (Lindstedt, 2005) and a discriminatory power and clustering capacity equivalent to PFGE (Malachowa et al., 2005).

The most widely characterized of $S$. aureus regulatory loci is the accessory gene regulator (agr) (Novick, 2003; Robinson et al., 2005; Wright et al., 2005). Within the agr locus there is a variable region comprising the $3^{\prime}$-end of the $\operatorname{agr} B$ gene, the $\operatorname{agr} D$ gene and the $5^{\prime}$-end of the $\operatorname{agr} C$ gene. S. aureus has been divided into four main agr genotypes based on this sequence variation (Gilot et al., 2002; Gilot \& van Leeuwen, 2004; Wright et al., 2005; Robinson et al., 2005). Associations between the agr genotype of isolates and specific staphylococcal diseases have been shown for toxic shock syndrome and staphylococcal scalded skin syndrome (Jarraud et al., 2002), and for abscesses and soft tissue infections in intravenous drug users (Monk et al., 2004).

A survey by the National Food Centre in Dublin into microbial contamination of Irish household refrigerators revealed that 298/726 (41\%) yielded S. aureus (Kennedy et al., 2005). Analysis of 157 isolates from this survey demonstrated that 101 (64\%) harboured at least two out of the sea, seb, seg and sei genes encoding enterotoxins with proven emetic activity (Smyth et al., 2006). However, the animal or human origins of these enterotoxigenic S. aureus remain uncertain. While a study of $S$. aureus from cows, sheep, goats, rabbits and chickens had revealed isolates with enterotoxin gene profiles identical to those from Irish domestic refrigerators (Smyth et al., 2005), no data were available on the frequencies of such genes in human carriage isolates in Ireland or on the population structure of Irish nasal isolates based on molecular typing methods.

In order to address this deficiency and thus enable epidemiological analysis, the present study was undertaken using PCR-based techniques (i) to characterize the enterotoxin (SE) and enterotoxin-like (SEl) gene profiles of $S$. aureus from a young, healthy Irish university student population, (ii) to determine the prevalence of the tst gene, encoding toxic shock syndrome toxin-1 (TSST-1), (iii) to group these isolates by agr typing, (iv) to determine the MLVA types and population structure, and (v) to ascertain the frequency of the $b b p$ gene, an allelic variant of the $s d r E$ gene amplified by the universal primers for $s d r$ genes analysed by MLVA.

\section{METHODS}

Strain collection. As part of student laboratory exercises from 1995 to 2004, nasal swabs were taken from science students, dental students and dental nursing/dental hygiene students. These swabs were plated on Mannitol Salt agar (Oxoid) and incubated for 36-48 h. Single, well-isolated colonies with the typical appearance of $S$. aureus were subcultured onto Tryptic Soya agar (Oxoid). Identification of these putative isolates as $S$. aureus was confirmed by sugar fermentation tests (arabinose, glucose, maltose, mannitol, sucrose, trehalose, xylose), the Voges-Proskauer test, DNase production, by a tube coagulase test using standard methods, and by the Staphaurex rapid latex test kit, which detects protein $\mathrm{A}$ and clumping factor (fibrinogen-binding protein) (Murex Diagnostics), according to the manufacturer's instructions. Primers specific for the femA gene encoding the $S$. aureus FemA peptidyltransferase (Schneider et al., 2004) and generating a $132 \mathrm{bp}$ amplimer were used for additional confirmation, as described by Mehrotra et al. (2000). Only isolates from students from the Republic of Ireland and Northern Ireland were retained.

Approximately $26-47 \%$ of the total number of nasal S. aureus isolates obtained in the years 1995, 1997, 2000 and 2002 were selected at random from those available. Only isolates from seven dental students were available for 2003, five of which were used. All of the isolates recovered during 2004 were included. The distribution of isolates by year of isolation was 1995, 7 isolates; 1997, 7 isolates; 2000, 8 isolates; 2002, 5 isolates; 2003, 5 isolates; and 2004, 16 isolates. The overall nasal carriage rate of the 492 students surveyed was $20.7 \%$, with a range of $17-31 \%$ of the Irish students sampled in any year. These rates are very similar to those reported for medical students in three different years at Trinity College Dublin (Kingdom et al., 1983). The numbers of isolates screened in this survey reflected approximately $10 \%$ of the students in each of the three student groups surveyed for $S$. aureus nasal carriage (15 isolates from 146 science students, 22 isolates from 245 dental science students, and 11 isolates from 101 dental nursing/dental hygiene students).

DNA extraction. Preparation of genomic DNA from S. aureus was performed as previously described (Fitzgerald et al., 1997). The procedure involved lysostaphin lysis, proteinase $\mathrm{K}$ treatment, addition of EDTA, Sarkosyl and cetyltrimethylammonium bromide (CTAB), extraction with chloroform/isoamyl alcohol and phenol/chloroform/ isoamyl alcohol, and precipitation with ethanol.

PCR. All primers were custom synthesized by MWG Biotech.

(i) MLVA. Primers used for MLVA were those described by Sabat et al. (2003). Primer pairs were tested individually and concentrations in the multiplex PCR primer mix optimized. Each multiplex PCR reaction contained 3-12 pmol of each primer. PCR was performed in a final volume of $25 \mu \mathrm{l}$. The PCR mix contained $16.2 \mu \mathrm{l} \mathrm{H}_{2} \mathrm{O}, 1 \mu \mathrm{l}$ dNTP mix $(0.2 \mu \mathrm{M}$ each dNTP), $0.3 \mu \mathrm{l}$ Taq DNA polymerase (5 $\mathrm{U}$ $\mu \mathrm{l}^{-1}$; Promega), $2.5 \mu \mathrm{l} 10 \times$ buffer $(10 \mathrm{mM}$ Tris/HCl, $\mathrm{pH} 9.0), 3 \mu \mathrm{l}$ $25 \mathrm{mM} \mathrm{MgCl}, 1 \mu \mathrm{l}$ genomic DNA sample, and $1 \mu \mathrm{l}$ primer mix. The thermal cycling conditions were those described by Sabat et al. (2003).

(ii) agr typing. An agr group-specific multiplex PCR was performed using the primers and thermal cycling conditions described by Gilot et al. (2002). The reaction mix contained 7-14 pmol of each primer. The following control strains for agr typing were kindly provided by university colleagues T. J. Foster and A. Rossney: strains Newman and COL (agr type I); strains MRSA252, MW2 and NCTC 8325-4 (agr type III) and strain RN4850 (agr type IV). Strain RF122 (agr type II) was from Fitzgerald et al. (2001).

(iii) $b b p$ gene. The primers employed to detect the $b b p$ gene encoding the bone sialoprotein-binding protein were those described by Tristan et al. (2003) using the thermal cycling conditions that Sabat et al. (2003) described for MLVA fingerprinting. The reaction mix contained 3-4 pmol of each primer. Strain MRSA252 was used as a positive control (Holden et al., 2004). 
(iv) SE and SEl genes. The standard nomenclature for SE (enterotoxin) and SEl (enterotoxin-like) genes recommended by Lina et al. (2004) is used throughout. All isolates were screened for the sea-see, seg-sei, selj-selo, selq and tst genes using the protocols and primers described by Smyth et al. (2005). These assays were done in a series of multiplex PCRs: mix 1, sea, sec, sed, see and $16 \mathrm{~S}$ rRNA genes; mix 2, seg, seh, sei, selj, tst and $16 \mathrm{~S}$ rRNA genes; mix 3, sell, selm, seln, selo, selq and 16S rRNA genes. The seb and selk genes were screened for using single PCRs. When egc locus-associated genes (seg, sei, selm, seln, selo) appeared to be missing from any isolate using multiplex PCR mix 2 or mix 3, individual PCRs were employed to recheck for these genes. The sei-seln intergenic region has been shown to harbour either two pseudogenes or the selu gene (Letertre et al., 2003). Accordingly, isolates that were positive for the egc locus were screened

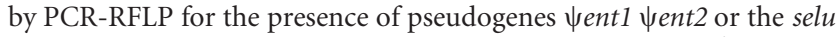
gene to provide data on their relative occurrence in $\mathrm{egc}^{+}$isolates (Letertre et al., 2003; Collery \& Smyth, 2007).

The 16S rRNA gene was amplified as a positive control for S. aureus DNA in all multiplex PCRs (Monday \& Bohach, 1999; Smyth et al., 2005). DNA from SE and SEl gene-positive control strains was included with these multiplex PCR tests: RF122 (sec-bovine, sell, tst) (Fitzgerald et al., 2001); NY19 (seb), FRI913 (sea, sec3, see, tst), FRI569 (seh), FRI472 (sed, seg, sei, selj), kindly provided by G. A. Bohach, University of Idaho, Moscow, USA, and A900322 (selo, selm, sei,

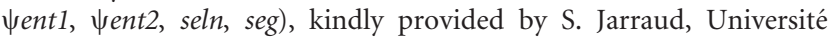
Lyon 1, Centre National de Référence des Staphylocoques, Lyon, France (Smyth et al., 2005). Strains A900322 and RF122 were used as

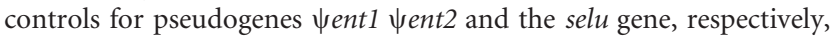
in PCR-RFLP (Collery \& Smyth, 2007).

(v) MLST. MLST was performed selectively on isolates from MLVA clusters and subclusters by PCR amplification of internal fragments of seven housekeeping genes by using a previously described procedure and primers (Enright et al., 2000). Sequencing of both DNA strands was performed commercially by Lark Technologies, using an automated Applied Biosystems 373A DNA sequencer, dye-labelled terminators and the primers used for PCR amplification. Analysis of sequences was performed using the BioNumerics software version 4.6 (Applied Maths). The alleles at each of the seven housekeeping loci were identified by comparing the sequences obtained from the test isolates with sequences held in the MLST database (http:// saureus.mlst.net). This database was also used to identify the allelic profile and hence the sequence type (ST) of each isolate. STs were assigned to clonal complexes (CCs) using the clustering algorithm eBURST (based upon related sequence types) (Feil et al., 2004; http:// eburst.mlst.net). Using eBURST, isolates with specific STs are assigned to a particular CC if they are related to at least one other ST in that CC at six out of the seven MLST loci used. Isolates that do not share alleles at six of the seven MLST loci with any other ST in the MLST database are deemed singletons.

Computer-assisted analyses of MLVA band profiles. All PCR products were analysed on $2 \%(\mathrm{w} / \mathrm{v})$ agarose gels, stained with ethidium bromide and visualized under UV light. For the purposes of generating dendrograms, PCR products from MLVA of $S$. aureus reference strain NCTC 8325-4, a derivative of a human isolate NCTC 8325 that is cured of prophages (Novick, 1967), were run in the first, middle and last lanes of gels as a universal gel standard. Computerassisted analyses of MLVA band profiles were performed using the DENDRON software package version 2.4 (Solltech) as described previously (Soll, 2000; Gee et al., 2002). Similarity coefficients $\left(S_{\mathrm{AB}} \mathrm{S}\right)$ based on band position alone were calculated for each pairwise combination of isolate patterns according to the formula $S_{\mathrm{AB}}=2 E /$ $(2 E+a+b)$, where $E$ is the number of bands shared by isolates $A$ and $\mathrm{B}, a$ is the number of bands unique to isolate $\mathrm{A}$, and $b$ is the number of bands unique to isolate $\mathrm{B}$. An $S_{\mathrm{AB}}$ of 1.00 represents identical patterns, and $S_{\mathrm{AB}}$ s ranging from 0.01 to 0.99 represent patterns with increasing proportions of bands at the same positions. Dendrograms were generated based on $S_{\mathrm{AB}}$ values using an unweighted pair-group method (Soll, 2000).

Statistics. Statistical significance was calculated using online calculators for the Fisher's exact test (http://www.matforsk.no/ola/ fisher.htm) or $\chi^{2}$ test (http://www.physics.csbsju.edu/stats/ contingency_NROW_NCOLUMN_form.html).

\section{RESULTS}

\section{SE, SEI and TSST-1 genes}

All of the 48 nasal isolates of S. aureus screened for $16 \mathrm{SE}$ and SEl genes possessed at least one of these; $66.7 \%$ had a classical SE gene (sea, seb, sec), of which 28 had a single gene and the remaining four had two of these genes in combination $\left(3 \mathrm{sea}^{+} \mathrm{seb}^{+}, 1 \mathrm{seb}^{+} \mathrm{sec}^{+}\right)$(Table 1). The commonest SE gene was seb, which was present in $75 \%$ of those possessing a classical SE gene. Of the isolates, $85.4 \%$ possessed the complete egc locus (selo, selm, sei, seln, seg); two other isolates lacked the sei gene and the seln and selo genes, respectively, as determined by both multiplex PCR and the use of primers for single genes (Table 1). The seh,

Table 1. Prevalence of enterotoxin genes, enterotoxin-like genes and the tst gene among 48 human nasal isolates of $S$. aureus

\begin{tabular}{|lcc|}
\hline Gene & No. of isolates & Percentage of isolates \\
\hline sea $^{*}$ & 8 & 16.7 \\
seb $^{*}$ & 24 & 50.0 \\
sec $\dagger$ & 4 & 8.3 \\
sed & 0 & 0 \\
see & 0 & 0 \\
seg & 43 & 89.6 \\
seh & 4 & 8.3 \\
sei & 42 & 87.5 \\
selj & 0 & 0 \\
selk & 3 & 6.3 \\
sell & 7 & 14.6 \\
selm & 43 & 89.6 \\
seln & 42 & 87.5 \\
selo & 42 & 87.5 \\
selq & 3 & 6.3 \\
tst & 6 & 12.5 \\
egc $\ddagger$ & 41 & 85.4 \\
Incomplete egc $\$$ & 2 & 4.2 \\
\hline
\end{tabular}

*Three strains possessed the sea and seb genes in combination. The sea gene is carried by serotype $\mathrm{F}$ lysogenic converting bacteriophage (Carroll et al., 1995).

$\dagger$ One isolate possessed the seb and sec genes in combination. $\ddagger$ Complete egc locus comprising the selo, selm, sei, seln and seg genes. $\$ e g c$ locus lacking the sei gene or the seln and selo genes by multiplex PCR and the use of primers for individual genes. 
selk, sell, selq and tst genes were each found in $<15 \%$ of isolates (Table 1).

The sei-seln intergenic region of the egc locus generally harbours two pseudogenes or the selu gene (Letertre et al., 2003). Of the 43 isolates with a complete or incomplete egc locus, $15(34.9 \%)$ possessed pseudogenes $\psi$ ent 1 and $\psi$ ent 2 and $19(44.2 \%)$ the selu gene as shown by PCR-RFLP (Collery \& Smyth, 2007). None of the remaining $9 \mathrm{egc}^{+}$ isolates, including the two with incomplete egc loci, gave PCR products with the primers of Letertre et al. (2003) despite several repeated attempts. Four of these 'nontypable' isolates lacked classical SE genes (1 egc only, 1 egc seh, 2 with incomplete egc loci). The other five 'nontypable' isolates all possessed the seb gene in combination with the egc locus (2 seb egc; 1 seb egc selk selq; 1 seb sea egc; 1 seb sec egc sell tst). Thomas et al. (2006) described isolates with $e g c$ loci harbouring insertion sequences and transposase genes, as well as an atypical $e g c$ locus with two new SEl genes, designated selu2 and selv, generated by a limited

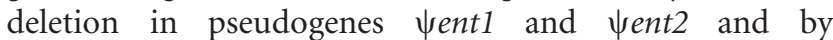
recombination between selm and sei, respectively. It is not known whether the primers described by Letertre et al. (2003) would type the sei-seln intergenic regions of such variant isolates.

The rates of occurrence of classical SE genes varied among the isolates examined from each of the six sampling years: $1995,1 \mathrm{seb}^{+}, 14.3 \%$; 1997, $5 \mathrm{seb}^{+}, 2 \mathrm{sea}^{+} \mathrm{seb}^{+}, 100 \%$; $2000,7 \mathrm{seb}^{+}, 87.5 \%$; 2002, $2 \mathrm{sea}^{+}, 1 \mathrm{seb}^{+}, 60 \%$; 2003, $2 \mathrm{seb}^{+}, 3 \mathrm{sec}^{+}, 100 \%$; and 2004, $3 \mathrm{sea}^{+}, 1 \mathrm{sea}^{+} \mathrm{seb}^{+}$, $4 \mathrm{seb}^{+}, 1 \mathrm{seb}^{+} \mathrm{sec}^{+}, 56.3 \%$. The differences in the numbers of isolates possessing classical SE genes between sampling years are statistically significant for 1995 versus 1997 and 1995 versus 2000 (Fisher's exact test, 2-tailed, $P=0.005$ and $P=0.01$, respectively). Humphreys et al. (1989) found that only $11.1 \%$ of 27 nasal isolates obtained from healthy medical students prior to arrival in hospitals for their clinical training and from biochemistry laboratory technicians in Dublin in the mid 1980s produced a classical SE (all SED-positive). Moreover, they found a statistically significant lower rate of SEB production among 17 community-acquired versus 35 hospital-acquired septicaemia isolates $(P<0.01)$. While the prior study tested for SEs and the present study for SE genes, the enterotoxin genotype data imply a real change in the rate of occurrence of $\mathrm{seb}^{+}$isolates in the community from the late 1990s compared to the mid 1980s through mid 1990s, coupled with a more frequent occurrence of $\mathrm{sea}^{+}$and $\mathrm{sec}^{+}$isolates. Carriage of the sed gene-bearing plasmid may have imposed a fitness cost that was ameliorated by its loss.

Sixteen of the 22 dental students ( $72.7 \%), 5$ of the 11 dental nursing/hygiene students ( $45.5 \%)$ and 9 of the 15 science students $(60.0 \%)$ yielded isolates bearing one or two classical SE genes. The differences in the carriage rates of isolates bearing classical SE genes between these student groups are not statistically significant. The somewhat higher occurrence of isolates bearing SE genes in the science and dental student groups may reflect the gender balance of these groups (see Methods) since male gender has been shown to be a candidate factor for persistent carriage in a student community (Bischoff et al., 2004). The numbers of isolates bearing sea: seb: sec enterotoxin genes among nasal isolates from the dental, dental nurse/ hygienist and science student groups were $3: 13: 3,1: 4: 0$ and $4: 7: 1$, respectively. The differences in the frequencies of these genes between the three student groups are not statistically significant.

\section{SE, SEI and TSST-1 gene combinations}

The two commonest gene combinations were the seb gene with the egc locus and the egc locus alone (complete and incomplete), found in 13 isolates $(27.1 \%)$ and in 12 isolates $(25 \%)$, respectively (Table 2 ). Twenty-seven of the 32 isolates $(84.4 \%)$ possessing a classical SE gene also had a complete egc locus. Of the five isolates possessing a classical SE gene but lacking the egc locus, two possessed the sea and seb genes together (one also with the selk and selq genes), and three possessed the seb gene only. The egc locus was present in 6 of the 8 isolates with the sea gene $(75 \%)-5$ of these carried the selu gene, in 19 of the 24 isolates with the seb gene $(79.2 \%)-9$ of these carried the selu gene, and in all 4 isolates with the sec gene - none of these carried the selu gene. Only 4 of the 14 isolates with a complete egc locus and lacking a classical enterotoxin gene had the selu gene. Neither of the isolates with an incomplete egc locus possessed a classical SE gene, additional SE or SEl genes, the tst gene or the selu gene.

Each of the six isolates containing the tst gene harboured at least one classical SE gene; all had the egc locus, three the selu gene, and three the sell gene. Of the three isolates possessing the selk-selq gene combination, two also had the seb gene and the egc locus (one with the selu gene), and the third isolate had the sea and seb genes. Of the four isolates with the seh gene, all had the egc locus - one with the selu gene, and two with the sea gene. All of the seven isolates with the sell gene had the egc locus - only one with the selu gene, three of which had classical SE genes - one with seb, one with seb and sec and one with sec-and the tst gene.

\section{agr genotyping}

The nasal isolates were agr genotyped (Table 2). The two commonest agr genotypes were types I and III. Only one strain was found to be of agr type IV. Eight of the agr type I isolates, seven of the agr type II isolates, 14 of the agr type III isolates and the single agr IV isolate harboured classical $\mathrm{SE}$ genes. These differences in the rates of occurrence of classical SE gene-positive isolates between agr genotypes I, II and III are not significant, nor are the rates of occurrence of individual classical SE genes between these agr types.

With respect to the commonest SE-SEl gene combination, namely seb egc, three isolates were of agr type I, four of agr type II, five of agr type III, and one of agr type IV (Table 2). 
Table 2. Prevalence of agr genotypes and SE, SEl and TSST1 genotypes among 48 human nasal isolates of $S$. aureus

\begin{tabular}{|c|c|c|c|}
\hline $\begin{array}{l}\text { agr } \\
\text { genotype }\end{array}$ & SE, SEl, TSST-1 genes & $\begin{array}{l}\text { No. of } \\
\text { isolates }\end{array}$ & $\begin{array}{l}\text { Percentage } \\
\text { of isolates* }\end{array}$ \\
\hline \multirow[t]{10}{*}{ Type I } & & 17 & 35.4 \\
\hline & sea†, seb & 1 & 5.9 \\
\hline & sea $\dagger$, seb, selk $\ddagger$ selq $\ddagger$ & 1 & 5.9 \\
\hline & sea $\dagger$, seb, egc\$ & 1 & 5.9 \\
\hline & $s e b, e g c$ & 3 & 17.6 \\
\hline & seb, selk, selq, egc & 2 & 11.8 \\
\hline & sec, sell, egc & 2 & 11.8 \\
\hline & seh, egc & 2 & 11.8 \\
\hline & sell, egc & 1 & 5.9 \\
\hline & $e g c$ & 4 & 23.5 \\
\hline \multirow[t]{5}{*}{ Type II } & & 12 & 25.0 \\
\hline & seb & 3 & 25.0 \\
\hline & $s e b, e g c$ & 4 & 33.3 \\
\hline & egc & 3 & 25.0 \\
\hline & egcll & 2 & 16.7 \\
\hline \multirow[t]{11}{*}{ Type III } & & 18 & 37.5 \\
\hline & sea $\dagger, e g c$ & 1 & 5.6 \\
\hline & sea $\dagger$, seh, egc & 2 & 11.1 \\
\hline & $s e a \dagger, e g c$, tst & 2 & 11.1 \\
\hline & $s e b, e g c$ & 5 & 27.8 \\
\hline & $s e b, e g c, t s t$ & 1 & 5.6 \\
\hline & seb, sell, egc, tst & 1 & 5.6 \\
\hline & seb, sec, sell, egc, tst & 1 & 5.6 \\
\hline & sec, sell, egc, tst & 1 & 5.6 \\
\hline & sell, egc & 1 & 5.6 \\
\hline & $e g c$ & 3 & 16.7 \\
\hline \multirow[t]{2}{*}{ Type IV } & & 1 & 2.1 \\
\hline & $s e b, e g c$ & 1 & 100.0 \\
\hline
\end{tabular}

${ }^{\star}$ Gene distribution within agr genotype calculated as percentage of isolates of that agr type.

$\dagger$ The sea gene is carried by serotype F lysogenic converting bacteriophage (Carroll et al., 1995).

¥The sek and seq genes occur along with the seb gene on a pathogenicity island (Orwin et al., 2002).

$\$$ Complete egc locus comprising the selo, selm, sei, seln and seg genes. IIIncomplete egc locus lacking either the sei gene or the seln and selo genes.

Of those with the complete egc locus alone, four isolates were of agr type I, and three each of agr types II and III. Of the seven harbouring the egc locus and the sell gene with or without a SE gene, three were of agr type I and four of $a g r$ type III. All six isolates with the tst gene were of agr type III. The difference in the rates of occurrence of the tst gene between agr types I, II and III is significant ( $\chi^{2}$ test, $P=0.017)$. The three isolates that contained the selk-sela gene combination were of agr type I. Both the seh and sell genes were only associated with agr types I and III (Table 2).

The isolates from dental students were distributed as follows: agr type I, 10, $45.5 \%$; agr type II, 5, $22.7 \%$; and $a g r$ type III, 7, $31.8 \%$. For the dental nurse/hygienist group the distribution was agr type I, 4, $36.4 \%$; agr type II, 2, $18.2 \%$; agr type III, 4, $36.4 \%$; and agr type IV, 1, 9.1\%. In the case of the science students the distribution was agr type I, 3, $20.0 \%$; agr type II, 5, $33.3 \%$; and agr type III, 7, $46.7 \%$. The differences in the rates of occurrence of agr genotypes I, II and III between these student groups are not significant. Nor are the differences in the rates of occurrence of the agr genotypes by year of isolation significant.

\section{bbp gene}

When MLVA fingerprinting was performed according to Sabat et al. (2003) on the 48 nasal isolates, the PCR band profiles of 28 isolates $(58.3 \%)$ revealed only five or six bands against the seven anticipated on the basis of the primer sets used to amplify seven genes, while a few strains produced eight bands (Fig. 1). These MLVA patterns were highly reproducible. The differences in the numbers of bands were subsequently associated with differences in the presence or absence of $s d r$ gene products. Sabat et al. (2006) reported that the PCR product of the $s d r C$ gene was always present, but that one or both of the $s d r D$ and $s d r E$ gene PCR products was absent in $58.9 \%$ of meticillinsensitive isolates from asymptomatic nasal carriers in the UK, the Netherlands and Poland. In the latter respect the present observations mirror that report.

Universal forward and reverse primers for the $s d r C$, $s d r D$ and $s d r E$ genes are used in the MLVA multiplex PCR of Sabat et al. (2003). The bbp gene is an allelic variant of the $s d r E$ gene (Tung et al., 2000). The A-regions of the Bbp and SdrE proteins show $76 \%$ amino acid sequence identity and the B-regions, 95-96\% identity (Tung et al., 2000). Using the BLAST program (http://www.ncbi.nlm.nih.gov/blast/), the universal forward and reverse $s d r$ primers of Sabat $e t$ al. (2003) have $100 \%$ matches for $b b p$ gene sequences of $S$. aureus strains 024 (Tung et al., 2000), MRSA252 (Holden et al., 2004) and NN1 (Otsuka et al., 2006).

As the primers used by Sabat et al. $(2003,2006)$ and Malachowa et al. (2005) do not distinguish the $s d r E$ gene from the $b b p$ gene, the frequency of the $b b p$ gene among the nasal isolates was determined using specific primers that do not match $s d r C D E$ gene sequences (Tristan et al., 2003). Twenty isolates were positive for the $b b p$ gene. None of the $b b p^{+}$isolates yielded five bands on MLVA fingerprinting, while 11 gave six bands, six gave seven bands, and three gave eight bands, indicating that the $b b p$ and $s d r E$ genes were both present in the latter three MLVA groups of isolates. The $b b p$ gene was present in one agr type I isolate (5.9\%), in 4 agr type II isolates $(33.3 \%)$, in 14 out of 18 agr type III isolates ( $77.8 \%$ ), and in the one agr type IV isolate. The differences in the frequencies of the $b b p$ gene between agr type III and agr types I and II are statistically significant (Fisher's exact test, 2-tailed, $P=0.00002$ and $P=0.025$, respectively). There were no associations between the occurrence of the $b b p$ gene and the $e g c$ locus or the $b b p$ gene and classical SE genes either taken together or separately. 

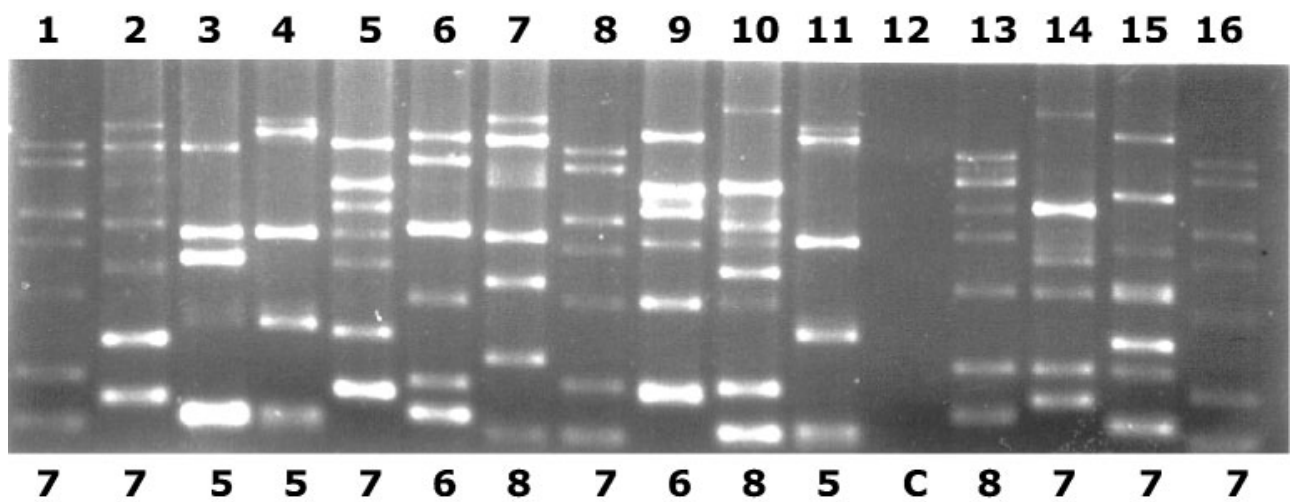

Fig. 1. MLVA of genetic polymorphisms within the $c l f A, c l f B, s d r C, s d r D, s d r E, s s p A, s p a$ and $b b p$ genes of nasal isolates of $S$. aureus. MLVA fingerprints of 12 nasal isolates are shown (lane numbers above gel: 2-7, 9-11 and 13-15). Lanes 1, 8 and 16 show the MLVA fingerprint of strain NCTC 8325-4 as an internal universal standard. Lane 12 shows a PCR negative control with no bacterial DNA present. The numbers of PCR products varied between five and eight (indicated below each lane). The differences in the number of bands are associated with differences at the $s d r$ and $b b p$ loci.

\section{MLVA typing}

The 48 S. aureus nasal isolates produced 47 MLVA patterns. $S_{\mathrm{AB}}$ values were computed for all possible pairwise combinations of isolates and the data used to construct a dendrogram showing the relationships between the nasal isolates (Fig. 2). The mean $S_{\mathrm{AB}}$ for 1128 pairwise comparisons was 0.25 . Examination of the dendrogram reveals that the isolates were divided into two clusters, designated I and II, comprising 11 and 37 of the isolates with mean $S_{\mathrm{AB}}$ S of $0.15 \pm 0.14$ and $0.29 \pm 0.21$, respectively. Seven of the cluster I isolates were of $a g r$ type I, three of $a g r$ type II, and one of agr type III. These isolates formed a heterogeneous population with limited relatedness.

MLVA cluster II could be subdivided into four subclusters, designated IIa to IId, at $S_{\mathrm{AB}}$ nodes of $0.37,0.24$ and 0.12 . There was a marked distribution of isolates according to agr type within these subgroups. Subgroup IIa contained 13 isolates of agr type III and the single isolate of agr type IV. Subgroup IIb comprised the remaining four isolates of agr type III, two isolates of agr type I and one isolate of $a g r$ type II. Subgroups IIc and IId each contained eight isolates, with four each of agr types I and II. Within MLVA cluster II, 21 of the 37 isolates formed nine pairs and one triplet of the same agr types at different $S_{\mathrm{AB}}$ nodes. In MLVA cluster I, four of the 11 isolates paired with respect to agr type at different $S_{\mathrm{AB}}$ nodes.

Subgroups IIa and IIb (mean $\mathrm{S}_{\mathrm{AB}}$ 0.71) are more related to each other than to subgroups IIc and IId (mean $S_{A B} 0.58$ ). The distribution of isolates of agr types I and II combined compared to agr types III and IV combined within MLVA subgroups IIa and IIb combined versus subgroups IIc and IId combined is highly statistically significant (Fisher's exact test, 2-tailed, $P=0.00000009$ ). Because of the strong association of the $b b p$ gene with agr type III, the distribution of $b b p^{+}$isolates within MLVA subgroups IIa and IIb combined versus subgroups IIc and IId combined is statistically significant (Fisher's exact test, 2-tailed, $P=0.00033$ )

Of the isolates of agr type III that possessed the tst gene, four were in subgroup IIa and two in subgroup IIb. However, there was no association between the MLVA clusters or the four subclusters and the SE-SEl genotypes of isolates or between the MLVA clusters or the four subclusters and their year of isolation or the student group from which they were isolated.

\section{MLST typing}

On the basis of the MLVA dendrogram, 13 of the Irish nasal isolates were selected for MLST typing - four from subcluster IIa (all agr type III) and two from subcluster IIb (both agr type III), two from subcluster IIc and two from subcluster IId (three agr type II, one agr type I), and three from cluster I (all agr type 1), reflecting 1:3 to $1: 4$ of the isolates in any cluster or subcluster. Selection within clusters or subclusters was based on diversity of enterotoxin gene profile and agr type.

The 13 isolates investigated were found to consist of 12 different STs, including seven novel STs (ST932, ST933, ST934, ST935, ST936, ST937 and ST938) (Fig. 2, Table 3). One novel aroE allele was found in ST937 and was designated 157. Using eBURST these $12 \mathrm{STs}$ belonged to five CCs (CC $30, n=5$; CC6, $n=2$; CC $5, n=1$; CC22, $n=1$; CC9, $n=1)$, and three were singletons.

Of the four isolates in subcluster IIa, two were ST30 (isolates MC15 and MC26) and one was ST484 (isolate MC19), a single locus variant (slv) of both ST30 and ST36 at the pta locus. The remaining isolate MC24 was of ST938, a slv of ST30 at the gmk locus. Three of the isolates formed pairs with other isolates with $S_{\mathrm{AB}} \mathrm{S}$ of $>0.82$ by MLVA and 

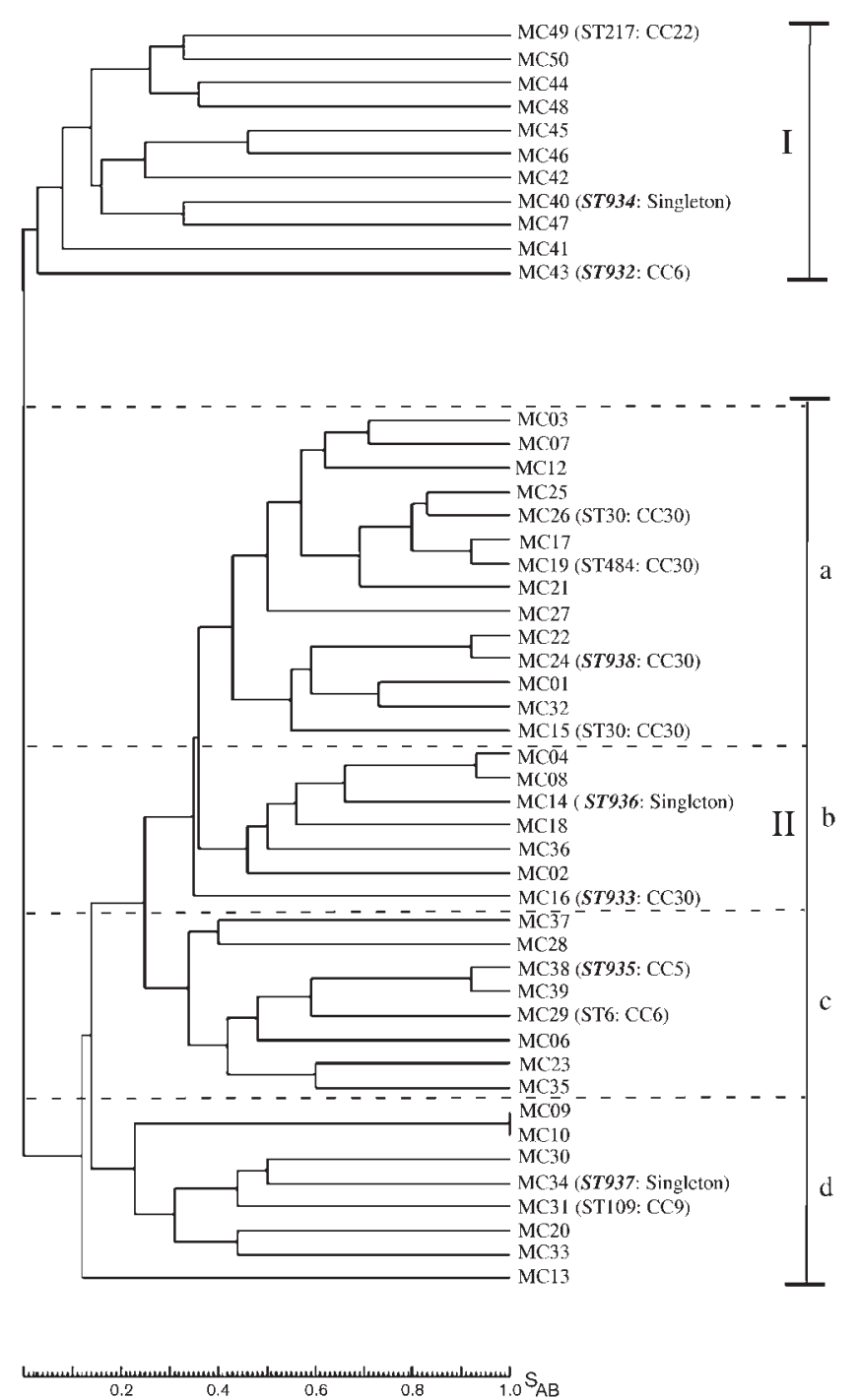

Fig. 2. Dendrogram generated from the $S_{A B}$ values computed for every possible pairwise combination of $48 S$. aureus nasal carriage isolates from an Irish university student population fingerprinted by MLVA. The $S_{A B}$ scale is shown below the dendrogram. On the basis of their MLVA fingerprints the isolates are divided into two main populations, designated I and II, comprising 11 and 37 of the isolates, respectively. MLVA population II can be further divided into four subclusters, designated Ila (14 isolates), Ilb (7 isolates), Ilc (8 isolates) and Ild (8 isolates), at $S_{A B}$ nodes of $0.37,0.24$ and 0.12 . Seventeen of the 18 agr type III isolates are in subgroups Ila and Ilb, while all the isolates in subgroups Ilc and IId are all of agr types I and II. Thirteen isolates were chosen for MLST analysis based on the major isolate groupings identified in the MLVA dendrogram. The sequence type (ST) and clonal complex (CC) of these isolates are shown in parentheses on the right of the figure. Table 3 shows the allelic profiles of the seven novel STs found in the present study, which are identified on the dendrogram in bold italics.

the fourth isolate, MC15, had an $S_{\mathrm{AB}}$ of 0.55 to one of these pairs. All belonged to CC 30 . Of those examined in subcluster IIb, isolate MC14 was ST936, a singleton with
Table 3. Allelic profiles of the seven novel STs found in the present study

\begin{tabular}{|c|c|c|c|c|c|c|c|}
\hline & $\operatorname{arcC}$ & aroE & glpF & $g m k$ & pta & $t p i$ & $y q i L$ \\
\hline ST932 & 12 & 4 & 1 & 4 & 1 & 1 & 3 \\
\hline ST933 & 2 & 2 & 2 & 1 & 2 & 2 & 2 \\
\hline ST934 & 18 & 18 & 6 & 1 & 13 & 15 & 7 \\
\hline ST935 & 1 & 4 & 2 & 4 & 12 & 1 & 10 \\
\hline ST936 & 2 & 45 & 2 & 6 & 2 & 2 & 2 \\
\hline ST937 & 1 & 157 & 1 & 1 & 11 & 5 & 11 \\
\hline ST938 & 2 & 2 & 2 & 6 & 6 & 3 & 2 \\
\hline
\end{tabular}

no close relatives in the database, and isolate MC16 was ST933, a slv of ST39 at the gmk locus and a member of CC30. Thus, of the six examined agr type III isolates within subclusters IIa and IIb, five belonged to CC30.

Of the two isolates in subcluster IIc, strain MC29 (agr type I) was of ST6 and the predicted ancestor of a small clonal complex, CC6. Strain MC38 (agr type II) was ST935, a slv of ST5 at the $g l p F$ locus, and belonged to CC5. Isolate MC31 (agr type II) in subcluster IId was ST109, a slv of ST9 at aroE, and thus belonged to CC9. The other isolate MC38 (agr type II) was ST937 and was predicted by eBURST to be a singleton.

Of the three isolates in subcluster I (all agr type I), strain MC49 was ST217, a slv of ST22 at the tpi locus, and belonged to CC22. Isolate MC43 was ST932, a slv of ST6 at the pta locus, and belongs to CC6. Isolate 40 was ST934 and predicted by eBURST to be a singleton. These isolates were distantly related by MLVA $\left(S_{\mathrm{AB}} \mathrm{S}\right.$ of $\left.0.04-0.14\right)$.

Thus, the more closely related isolates by MLVA (subclusters IIa and IIb) belonged to the same CC, while those in more distantly related MLVA groups (cluster I and subclusters IIc and IId) belonged to diverse CCs. Indeed, Malachowa et al. (2005) found the overall correlation between MLVA clusters and MLST CCs to be lower than between MLVA and PFGE clusters and MLVA and spa typing clusters.

\section{DISCUSSION}

Few data are available on SE and TSST-1 production by or on the presence of SE, SEl and TSST-1 genes in Irish human isolates of S. aureus (Humphreys et al., 1989; Aucken et al., 2006) or in animal isolates (Fitzgerald et al., 2000; Smyth et al., 2005, 2006). Herein $100 \%$ of nasal isolates from a young, healthy, Irish university student population collected over a 10 -year period harboured a SE and/or SEl gene, $66.7 \%$ possessing at least one classical SE gene and $89.6 \%$, a complete or incomplete egc locus. Of the isolates harbouring a classical SE gene, $84.4 \%$ had a complete egc locus. In contrast to the findings of Humphreys et al. (1989) on SED production, no isolate possessed the sed gene. 
Five groups in Germany, Japan, Poland, New Zealand and Bulgaria have screened nasal carriage isolates for 12-18 of the SE and SEl genes in S. aureus discovered at the time of the present study (Becker et al., 2003, 2004; Omoe et al., 2005; Bania et al., 2006; Boerema et al., 2006; Nashev et al., 2007). Comparison of these studies with the findings herein brings out several points. The percentage of isolates possessing an SE or SEl gene varied from 75 to $100 \%$. The proportion bearing a classical SE gene ranged from 30 to $67 \%$. The predominant classical SE gene varied from country to country - Ireland, seb; Germany, sea, sec; Japan, seb; New Zealand, seb; Poland, sec; and Bulgaria, sea. Moreover, of isolates with a classical SE gene, those possessing a complete (and incomplete) egc locus ranged from 38 to $84 \%$ between these studies. Differences in the nature of the study population screened for nasal carriage, i.e. healthy individuals versus patients, and differences in PCR screening methodologies, e.g. primers, amplification cycles, single versus multiplex PCR (Monday \& Bohach, 1999; Jarraud et al., 2001; Becker et al., 2003, 2004; Chen et al., 2004; Smyth et al., 2005; Bania et al., 2006), may contribute to such variations, and as indeed may the makes of the thermal cyclers used (Saunders et al., 2001; Schoder et al., 2005).

Differences in the frequencies of incomplete egc loci among nasal isolates are particularly notable $-38.1 \%$ (Becker et al., 2003, 2004), $12.4 \%$ (Omoe et al., 2005), 5 \% (Boerema et al., 2006), 0\% (Bania et al., 2006), 11.1\% (Nashev et al., 2007) and $4.2 \%$ herein. In an extensive study of human isolates collected during 2001-2003 from suppurative infections, acute toxaemia and asymptomatic nasal carriage, Thomas et al. (2006) found incomplete egc loci to be uncommon (3.8 \% of egc gene-positive isolates). While the Polish, New Zealand and Bulgarian investigations (Bania et al., 2006; Boerema et al., 2006; Nashev et al., 2007) tested for $e g c$ locus genes individually, neither the Japanese study nor the German studies (Becker et al., 2003, 2004; Omoe et al., 2005) stated that they rechecked their egc loci with 'missing' genes using individual sets of primers. Detection of egc genes by PCR may be limited by primer specificity for individual alleles (Monday \& Bohach, 1999; Jarraud et al., 2001; Becker et al., 2003, 2004; Smyth et al., 2005; Bania et al., 2006) as sequence variants of the seg, sei and seln genes have been described (Abe et al., 2000; Letertre et al., 2003; Blaiotta et al., 2004).

The frequency of the seh gene in nasal isolates is generally low: $4.3 \%$ (Jarraud et al., 2002), $16.7 \%$ and $4.1 \%$ in Japan (Omoe et al., 2002, 2005), $3.8 \%$ in Poland (Bania et al., 2006), $6.2 \%$ in Germany (Becker et al., 2003), $20 \%$ in New Zealand (Boerema et al., 2006), $6.7 \%$ in Bulgaria (Nashev et al., 2007) and $8.3 \%$ herein. The selq gene is present on the SaPI3 pathogenicity island directly $5^{\prime}$ of the selk gene and together with the seb gene (Orwin et al., 2002). In nasal isolates the frequency of the selk selq gene combination is low: $5 \%$ in Poland (Bania et al., 2006), 6.2\% in Japan (Omoe et al., 2005) and $6.3 \%$ herein. The rates of occurrence of the tst gene in nasal isolates are fairly consistent $-12.4 \%$ in Japan (Omoe et al., 2005), $12.5 \%$ in Poland (Bania et al., 2006), 22.4\% in Germany (Becker et al., 2003), $24.3 \%$ in the USA (Mehrotra et al., 2000) and $13.7 \%$ herein.

In two studies of nasal carriage isolates, the agr type distributions were: agr type I, $55.2 \%$ and $52.3 \%$, versus $35.4 \%$ herein; agr type II, $25.9 \%$ and $29.2 \%$, versus $25.0 \%$ herein; agr type III, $17.2 \%$ and $10.8 \%$, versus $37.5 \%$ herein; and agr type IV, $0 \%$ and $7.7 \%$, versus $2.1 \%$ herein (Cespedes et al., 2005; Lina et al., 2003). In a study of nasal isolates from children and their guardians, Shopsin et al. (2003) reported that the distribution of the four agr groups was agr type I, $41.6 \%$; agr type II, $24.7 \%$; agr type III, $33.8 \%$; and agr type IV, $0 \%$; this is somewhat similar to that found in the present study. All of the Irish isolates possessing the tst gene were of agr type III and belonged to MLVA subgroups IIa and IIb, four of these isolates possessing the $b b p$ gene.

The diversity in the numbers of bands produced on MLVA fingerprinting had been unexpected, as such observations had not been specifically annotated in the original report of Sabat et al. (2003). Subsequently, Sabat et al. (2006) reported that, while all 142 MLVA-typed nasal isolates possessed the $s d r C$ gene, only $55(38.7 \%)$ of these were both $s d r D$ - and $s d r E$-positive, $76(53.5 \%)$ had the $s d r E$ gene but not the $s d r D$ gene, $3(2.1 \%)$ had the $s d r D$ but not the $s d r E$ gene, and $8(5.6 \%)$ lacked both the $s d r D$ and $s d r E$ genes, i.e. $94.4 \%$ would yield six or seven bands versus 40 out of 48 nasal isolates ( $83.3 \%$ ) yielding six to eight bands herein. The percentage of isolates herein possessing the $b b p$ gene $(41.7 \%)$ is somewhat higher than that reported by Tristan et al. (2003) for nasal isolates (20.7\%).

Three isolates yielding eight bands on MLVA typing were $b b p$-positive. While the $s d r E$ and $b b p$ alleles have been found separately in isolates (Otsuka et al., 2006; Stephens et al., 2006; Taneike et al., 2006), their dual occurrence has only been previously recorded in a single communityacquired MRSA isolate NN13 (Otsuka et al., 2006). However, seven isolates belonging to CC30 of MLST types ST36, ST30 and ST39 have been found to possess the $s d r E$ and $b b p$ genes with $b b p$ arranged tandemly immediately downstream of $s d r E$ (Dr Edward Feil, University of Bath, personal communication). The three isolates in the present study possessing the $s d r E$ and $b b p$ alleles all had the seb gene and the egc locus with the seluv gene (Letertre et al., 2003; M. M. Collery, unpublished data), were of agr type III and grouped in MLVA subclusters IIa and IIb, two of them being confirmed to belong to CC30 by MLST.

The association seen between MLVA subgroups and agr genotype has not been previously recorded, although MLVA clusters have been shown to match well with those obtained by PFGE and to be consistent with spa typing (Malachowa et al., 2005). PFGE patterns and agr types have been shown to be linked within certain CCs (Goerke et al., 2005). PFGE has also revealed a pronounced diversity among nasal carriage isolates and that isolates (non-MRSA) from 
unrelated individuals yield unique patterns ( $\mathrm{Hu}$ et al., 1995; Cespedes et al., 2005).

The Irish nasal carriage isolates investigated in the present study belonged to diverse genotypes as determined by MLST analysis. They yielded 12 distinct STs, seven of which had not been described previously. Furthermore, 3 of the 13 isolates were singletons and the remainder belonged to five CCs, the most common being CC30. Interestingly, three of these CCs comprised major pandemic clones, i.e. CC30, CC5 and CC22, whereas the other two, CC6 and CC9, belonged to minor lineages. Grundmann et al. (2002) previously identified S. aureus isolates of CC30, CC22, CC5 and CC9 among nasal carriage isolates in the UK, similar to the present study. They also identified CC30 as the commonest, accounting for $25.6 \%$ of the nasal isolates examined. In addition, Peacock et al. (2002) reported that 26-33\% of nasal isolates from a cohort of renal dialysis outpatients on any of three sampling occasions belonged to CC30. Based on the selective MLST typing of isolates within subclusters IIa and IIb herein, a similar overall percentage of nasal isolates would be predicted to belong to CC30.

As the outbreak incidence of food-borne disease declines, monitoring sporadic cases of staphylococcal food poisoning will be an important challenge for the 21st century (Mead et al., 1999). The molecular genetic definition of a population of nasal carriage isolates from a healthy Irish population together with data on molecular genotyping of animal isolates (Smyth et al., 2005) and of S. aureus from contaminated Irish domestic refrigerators (Smyth et al., 2006) should add to the knowledge base for epidemiological analysis of staphylococcal food poisoning incidents in Ireland and of the roles, which are possibly underestimated, of the more newly described SEs and possibly SEls in this toxin-mediated syndrome.

\section{ACKNOWLEDGEMENTS}

Mark Collery was in receipt of a studentship from the Sarah Purser Medical Research Fund and of a Trinity College postgraduate research studentship. Davida Smyth was supported by a Teagasc Walsh Fellowship. Anna Shore was supported by Health Research Board Grant TRA/ 2006/4 and by the Microbiology Research Unit, Dublin Dental School \& Hospital. Thanks to Karsten Becker and Ed Feil, who provided helpful additional and unpublished data, respectively, to our University colleagues Tim Foster and Angela Rossney, who provided the control strains for agr typing, and to Greg Bohach and Sophie Jarraud, who originally provided the control strains for SE and SEl gene detection.

\section{REFERENCES}

Abe, J., Ito, Y., Onimaru, M., Kohsaka, T. \& Takeda, T. (2000). Characterization and distribution of a new enterotoxin-related superantigen produced by Staphylococcus aureus. Microbiol Immunol 44, 79-88.

Arshad, M. F., Dunn, F. J., Vega, R., Valvano, J. W. \& Serwer, P. (1993). Progress in developing improved programs for pulsed field agarose gel electrophoresis of DNA. Electrophoresis 14, 344-348.
Aucken, H. M., O’Neill, G., Ganner, M., Dinerstein, N., Ali, M. \& Murchan, S. (2006). Irish-1 and Irish-2: UK-epidemic meticillinresistant Staphylococcus aureus strains associated with Northern Ireland. J Hosp Infect 63, 170-178.

Bania, J., Dabrowska, A., Korzekwa, K., Zarczynska, A., Bystron, J., Chrzanowska, J. \& Molenda, J. (2006). The profiles of enterotoxin genes in Staphylococcus aureus from nasal carriers. Lett Appl Microbiol 42, 315-320.

Becker, K., Friedrich, A. W., Lubritz, G., Weilert, M., Peters, G. \& von Eiff, C. (2003). Prevalence of genes encoding pyrogenic toxin superantigens and exfoliative toxins among strains of Staphylococcus aureus isolated from blood and nasal specimens. J Clin Microbiol 41, 1434-1439.

Becker, K., Friedrich, A. W., Peters, G. \& von Eiff, C. (2004). Systematic survey on the prevalence of genes coding for staphylococcal enterotoxins SElM, SElO, and SElN. Mol Nutr Food Res 48, 488-495.

Bischoff, W. E., Wallis, M. L., Tucker, K. B., Reboussin, B. A. \& Sherertz, R. J. (2004). Staphylococcus aureus nasal carriage in a student community: prevalence, clonal relationships, and risk factors. Infect Control Hosp Epidemiol 25, 485-491.

Blaiotta, G., Ercolini, D., Pennacchia, C., Fusco, V., Casaburi, A., Pepe, O. \& Villani, F. (2004). PCR detection of staphylococcal enterotoxin genes in Staphylococcus spp. strains isolated from meat and dairy products. Evidence for new variants of $s e \mathrm{G}$ and $s e \mathrm{I}$ in $S$. aureus AB-8802. J Appl Microbiol 97, 719-730.

Boerema, J. A., Clemens, R. \& Brightwell, G. (2006). Evaluation of molecular methods to determine enterotoxigenic status and molecular genotype of bovine, ovine, human and food isolates of Staphylococcus aureus. Int J Food Microbiol 107, 192-201.

Carroll, D., Kehoe, M. A., Cavanagh, D. \& Coleman, D. C. (1995). Novel organization of the site-specific integration and excision recombination functions of the Staphylococcus aureus serotype F virulence-converting phages $\Phi 13$ and $\Phi 42$. Mol Microbiol 16, 877-893.

Cespedes, C., Saïd-Salim, B., Miller, M., Lo, S.-H., Kreiswirth, B. N., Gordon, R. J., Vavagiakis, P., Klein, R. S. \& Lowy, F. D. (2005). The clonality of Staphylococcus aureus nasal carriage. J Infect Dis 191, 444-452.

Chen, T.-R., Chiou, C.-S. \& Tsen, H.-Y. (2004). Use of novel PCR primers specific to the genes of staphylococcal enterotoxin $G, H$, I for the survey of Staphylococcus aureus strains isolated from food-poisoning cases and food samples in Taiwan. Int J Food Microbiol 92, 189-197.

Collery, M. M. \& Smyth, C. J. (2007). Rapid differentiation of Staphylococcus aureus isolates harbouring egc loci with pseudogenes $\psi e n t 1$ and $\psi e n t 2$ and the selu or seluv gene using PCR-RFLP. J Med Microbiol 56, 208-216.

Enright, M. C., Day, N. P. J., Davies, C. E., Peacock, S. J. \& Spratt, B. J. (2000). Multilocus sequence typing for characterization of methicillin-resistant and methicillin-susceptible clones of Staphylococcus aureus. J Clin Microbiol 38, 1008-1015.

Feil, E. J., Li, B. C., Aanensen, D. M., Hanage, W. P. \& Spratt, B. J. (2004). eBURST: inferring patterns of evolutionary descent among clusters of related bacterial genotypes with multilocus sequence typing data. J Bacteriol 186, 1518-1530.

Ferry, T., Perpoint, T., Vandenesch, F. \& Etienne, J. (2005). Virulence determinants in Staphylococcus aureus and their involvement in clinical syndromes. Curr Infect Dis Rep 7, 420-428.

Fitzgerald, J. R., Meaney, W. J., Hartigan, P. J., Smyth, C. J. \& Kapur, V. (1997). Fine-structure molecular epidemiological analysis of Staphylococcus aureus recovered from cows. Epidemiol Infect 119, 261-269.

Fitzgerald, J. R., Hartigan, P. J., Meaney, W. J. \& Smyth, C. J. (2000). Molecular population and virulence factor analysis of Staphylococcus 
aureus from bovine intramammary infection. J Appl Microbiol 88, $1028-1037$.

Fitzgerald, J. R., Monday, S. R., Foster, T. J., Bohach, G. A., Hartigan, P. J., Meaney, W. J. \& Smyth, C. J. (2001). Characterization of a putative pathogenicity island from bovine Staphylococcus aureus encoding multiple superantigens. J Bacteriol 183, 63-70.

Francois, P., Huyghe, A., Charbonnier, Y., Bento, M., Herzig, S., Topolski, I., Fleury, B., Lew, D., Vaudaux, P. \& other authors (2005). Use of an automated multiple-locus, variable-number tandem repeatbased method for rapid and high-throughput genotyping of Staphylococcus aureus. J Clin Microbiol 43, 3346-3355.

Gee, S. F., Joly, S., Soll, D. R., Meis, J. F. G. M., Verweij, P. E., Polacheck, I., Sullivan, D. J. \& Coleman, D. C. (2002). Identification of four distinct genotypes of Candida dubliniensis and detection of microevolution in vitro and in vivo. J Clin Microbiol 40, 556-574.

Gilot, P. \& van Leeuwen, W. (2004). Comparative analysis of agr locus diversification and overall genetic variability among bovine and human Staphylococcus aureus isolates. J Clin Microbiol 42, 1265-1269.

Gilot, P., Lina, G., Cochard, T. \& Poutrel, B. (2002). Analysis of the genetic variability of genes encoding the RNA III-activating components Agric and TRAP in a population of Staphylococcus aureus strains isolated from cows with mastitis. J Clin Microbiol 40, 4060-4067.

Goerke, C., Esser, S., Kummel, M. \& Wolz, C. (2005). Staphylococcus aureus strain designation by agr and cap polymorphism typing and delineation of agr diversification by sequence analysis. Int $\mathrm{J} \mathrm{Med}$ Microbiol 295, 67-75.

Grundmann, H., Hori, S., Enright, M. C., Webster, C., Tami, A., Feil, E. J. \& Pitt, T. (2002). Determining the genetic structure of the natural population of Staphylococcus aureus: a comparison of multilocus sequence typing with pulsed-field gel electrophoresis, randomly amplified polymorphic DNA analysis, and phage typing. J Clin Microbiol 40, 4544-4546.

Holden, M. T. G., Feil, E. J., Lindsay, J. A., Peacock, S. J., Day, N. P. J., Enright, M. C., Foster, T. J., Moore, C. E., Hurst, L. \& other authors (2004). Complete genomes of two clinical Staphylococcus aureus strains: evidence for the rapid evolution of virulence and drug resistance. Proc Natl Acad Sci U S A 101, 9786-9791.

Hu, L., Umeda, A., Kondo, S. \& Amako, K. (1995). Typing of Staphylococcus aureus colonising human nasal carriers by pulsed-field gel electrophoresis. J Med Microbiol 42, 127-132.

Humphreys, H., Keane, C. T., Hone, R., Pomeroy, H., Russell, R. J., Arbuthnott, J. P. \& Coleman, D. C. (1989). Enterotoxin production by Staphylococcus aureus isolates from cases of septicaemia and from healthy carriers. J Med Microbiol 28, 163-172.

Jarraud, S., Peyrat, M. A., Lim, A., Tristan, A., Bes, M., Mougel, C., Etienne, J., Vandenesch, F., Bonneville, M. \& Lina, G. (2001). egc, a highly prevalent operon of enterotoxin gene, forms a putative nursery of superantigens in Staphylococcus aureus. J Immunol 166, 669-677 (Enterotoxin Nomenclature Correction: J Immunol 166, 4260).

Jarraud, S., Mougel, C., Thioulouse, J., Lina, G., Meugnier, H., Forey, F., Nesme, X., Etienne, J. \& Vandenesch, F. (2002). Relationships between Staphylococcus aureus genetic background, virulence factors, agr groups (alleles), and human disease. Infect Immun 70, 631-641.

Kennedy, J., Jackson, V., Blair, I. S., McDowell, D. A., Cowan, C. \& Bolton, D. J. (2005). Food safety knowledge of consumers and the microbiological and temperature status of their refrigerators. J Food Prot 68, 1421-1430.

Kingdom, J. C. P., Joyce, S. M., Bradley, F. L., Jauch, W., Falkiner, F. R. \& Keane, C. T. (1983). Staphylococcal nasal carriage in medical students with varying clinical exposure. J Hosp Infect 4, 75-79.
Kluytmans, J., van Belkum, A. \& Verbrugh, H. (1997). Nasal carriage of Staphylococcus aureus: epidemiology, underlying mechanisms, and associated risks. Clin Microbiol Rev 10, 505-520.

Letertre, C., Perelle, S., Dilasser, F. \& Fach, P. (2003). Identification of a new putative enterotoxin SEU encoded by the egc cluster of Staphylococcus aureus. J Appl Microbiol 95, 38-43.

Lina, G., Boutite, F., Tristan, A., Bes, M. \& Vandenesch, F. (2003). Bacterial competition for human nasal cavity colonization: role of staphylococcal agr alleles. Appl Environ Microbiol 69, 18-23.

Lina, G., Bohach, G. A., Nair, S. P., Hiramatsu, K., Jouvin-Marche, E. \& Mariuzza, R. (2004). Standard nomenclature for the superantigens expressed by Staphylococcus. J Infect Dis 189, 2334-2336.

Lindstedt, B.-A. (2005). Multiple-locus variable number tandem repeats analysis for genetic fingerprinting of pathogenic bacteria. Electrophoresis 26, 2567-2582.

Malachowa, N., Sabat, A., Gniadkowski, M., Krzyszton-Russjan, J., Empel, J., Miedzobrodzki, J., Kosowska-Shick, K., Appelbaum, P. C. \& Hryniewicz, W. (2005). Comparison of multiple-locus variablenumber tandem-repeat analysis with pulsed-field gel electrophoresis, spa typing, and multilocus sequence typing for clonal characterization of Staphylococcus aureus isolates. J Clin Microbiol 43, 3095-3100.

Mead, P. S., Slutsker, L., Dietz, V., McCaig, L. F., Bresee, J. S., Shapiro, C., Griffin, P. M. \& Tauxe, R. V. (1999). Food-related illness and death in the United States. Emerg Infect Dis 5, 607-625.

Mehrotra, M., Wang, G. \& Johnson, W. M. (2000). Multiplex PCR for detection of genes for Staphylococcus aureus enterotoxins, exfoliative toxins, toxic shock syndrome toxin 1 , and methicillin resistance. J Clin Microbiol 38, 1032-1035.

Monday, S. R. \& Bohach, G. A. (1999). Use of multiplex PCR to detect classical and newly described pyrogenic exotoxin genes in staphylococcal isolates. J Clin Microbiol 37, 3411-3414.

Monk, A. B., Curtis, S., Paul, J. \& Enright, M. C. (2004). Genetic analysis of Staphylococcus aureus from intravenous drug user lesions. J Med Microbiol 53, 223-227.

Murray, R. J. (2005). Recognition and management of Staphylococcus aureus toxin-mediated disease. Intern Med J 35 (Suppl. 2), S106-S109.

Nashev, D., Toshkova, K., Bizeva, L., Akineden, Ö., Lämmler, C. \& Zschöck, M. (2007). Distribution of enterotoxin genes among carriage- and infection-associated isolates of Staphylococcus aureus. Lett Appl Microbiol 45, 681-685.

Nouwen, J., Boelens, H., van Belkum, A. \& Verbrugh, H. (2004). Human factor in Staphylococcus aureus nasal carriage. Infect Immun 72, 6685-6688.

Novick, R. P. (1967). Properties of a cryptic high-frequency transducing phage in Staphylococcus aureus. Virology 33, 155-166.

Novick, R. P. (2003). Autoinduction and signal transduction in the regulation of staphylococcal virulence. Mol Microbiol 48, 1429-1449.

Omoe, K., Ishikawa, M., Shimoda, Y., Hu, D.-L., Ueda, S. \& Shinagawa, K. (2002). Detection of seg, seh, and sei genes in Staphylococcus aureus isolates and determination of the enterotoxin productivities of $S$. aureus isolates harboring seg, seh, or sei genes. $J$ Clin Microbiol 40, 857-862.

Omoe, K., Hu, D.-L., Takahashi-Omoe, H., Nakane, A. \& Shinagawa, K. (2005). Comprehensive analysis of classical and newly described staphylococcal superantigenic toxin genes in Staphylococcus aureus isolates. FEMS Microbiol Lett 246, 191-198.

Orwin, P. M., Leung, D. Y. M., Tripp, T. J., Bohach, G. A., Earhart, C. A., Ohlendorf, D. H. \& Schlievert, P. M. (2002). Characterization of a novel staphylococcal enterotoxin-like superantigen, a member of the group V subfamily of pyrogenic toxins. Biochemistry 41, 14033-14040. 
Otsuka, T., Saito, K., Dohmae, S., Takano, T., Higushi, W., Takizawa, Y., Okubo, T., Iwakura, N. \& Yamamoto, T. (2006). Key adhesion gene in community-acquired methicillin-resistant Staphylococcus aureus. Biochem Biophys Res Commun 346, 1234-1244.

Peacock, S. J., de Silva, I. \& Lowy, F. D. (2001). What determines nasal carriage of Staphylococcus aureus? Trends Microbiol 9, 605-610.

Peacock, S. J., de Silva, G. D. I., Justice, A., Cowland, A., Moore, C. E., Winearls, C. G. \& Day, N. P. J. (2002). Comparison of multilocus sequence typing and pulsed-field gel electrophoresis as tools for typing Staphylococcus aureus in a microepidemiological setting. J Clin Microbiol 40, 3764-3770.

Robinson, D. A. \& Enright, M. C. (2004). Multilocus sequence typing and the evolution of methicillin-resistant Staphylococcus aureus. Clin Microbiol Infect 10, 92-97.

Robinson, D. A., Monk, A. B., Cooper, J. E., Feil, E. J. \& Enright, M. C. (2005). Evolutionary genetics of the accessory gene regulator (agr) locus in Staphylococcus aureus. J Bacteriol 187, 8312-8321.

Sabat, A., Krzyszton-Russjan, J., Strzalka, W., Filipek, R., Kosowska, K., Hryniewicz, W., Travis, J. \& Potempa, J. (2003). New method for typing Staphylococcus aureus strains: multiple-locus variable-number tandem repeat analysis of polymorphism and genetic relationships of clinical isolates. J Clin Microbiol 41, 1801-1804.

Sabat, A., Melles, D. C., Martirosian, G., Grundmann, H., van Belkum, A. \& Hryniewicz, W. (2006). Distribution of the serine-aspartate repeat protein-encoding $s d r$ genes among nasal-carriage and invasive Staphylococcus aureus strains. J Clin Microbiol 44, 1135-1138.

Saunders, G. C., Dukes, J., Parkes, H. C. \& Cornett, J. H. (2001). Interlaboratory study on thermocycler performance in controlled PCR and random amplified polymorphic DNA analyses. Clin Chem 47, 47-55.

Schneider, T., Senn, M. M., Berger-Bächi, B., Tossi, A., Sahl, H.-G. \& Wiedemann, I. (2004). In vitro assembly of a complete, pentaglycine interpeptide bridge containing cell wall precursor (lipid II-Gly5) of Staphylococcus aureus. Mol Microbiol 53, 675-685.

Schoder, D., Schmalwiesser, A., Schauberger, G., Hoorfar, J., Kuhn, M. \& Wagner, M. (2005). Novel approach for assessing performance of PCR cyclers used for diagnostic testing. J Clin Microbiol 43, 2724-2728.

Shopsin, B. \& Kreiswirth, B. N. (2001). Molecular epidemiology of methicillin-resistant Staphylococcus aureus. Emerg Infect Dis 7, 323-326.

Shopsin, B., Mathema, B., Alcabes, P., Said-Salim, B., Lina, G., Matsuka, A., Martinez, J. \& Kreiswirth, B. (2003). Prevalence of agr specificity groups among Staphylococcus aureus strains colonizing children and their guardians. J Clin Microbiol 41, 456-459.

Smyth, D. S., Hartigan, P. J., Meaney, W. J., Fitzgerald, J. R., Deobald, C. F., Bohach, G. A. \& Smyth, C. J. (2005). Superantigen genes encoded by the egc cluster and SaPlbov are predominant among
Staphylococcus aureus isolates from cows, goats, sheep, rabbits and poultry. J Med Microbiol 54, 401-411.

Smyth, D. S., Kennedy, J., Twohig, J., Miajlović, H., Bolton, D. \& Smyth, C. J. (2006). Staphylococcus aureus isolates from Irish domestic refrigerators possess novel enterotoxin and enterotoxin-like genes and are clonal in nature. J Food Prot 69, 508-515.

Soll, D. R. (2000). The ins and outs of DNA fingerprinting the infectious fungi. Clin Microbiol Rev 13, 332-370.

Stephens, A. J., Huygens, F., Inman-Bamber, J., Price, E. P., Nimmo, G. R., Schooneveldt, J., Munckhof, W. \& Giffard, P. M. (2006). Methicillin-resistant Staphylococcus aureus genotyping using a small set of polymorphisms. J Med Microbiol 55, 43-51.

Taneike, I., Otsuka, T., Dohmae, S., Saito, K., Ozaki, K., Takano, M., Higushi, W., Takano, T. \& Yamamoto, T. (2006). Molecular nature of methicillin-resistant Staphylococcus aureus derived from explosive nosocomial outbreaks of the 1980s in Japan. FEBS Lett 580, 2323-2334.

Thomas, D. Y., Jarraud, S., Lemercier, B., Cozon, G., Echasserieau, K., Etienne, J., Gougeon, M.-L., Lina, G. \& Vandenesch, F. (2006). Staphylococcal enterotoxin-like toxins U2 and V, two new staphylococcal superantigens arising from recombination within the enterotoxin gene cluster. Infect Immun 74, 4724-4734.

Todd, J. K. (2005). Staphylococcal infections. Pediatr Rev 26, 444-450. Trindade, P. A., McCulloch, J. A., Oliviera, G. A. \& Mamizuka, E. M. (2003). Molecular techniques for MRSA typing: current issues and perspectives. Braz J Infect Dis 7, 32-43.

Tristan, A., Ying, L., Bes, M., Etienne, J., Vandenesch, F. \& Lina, G. (2003). Use of multiplex PCR to identify Staphylococcus aureus adhesins involved in human hematogenous infections. J Clin Microbiol 41, 4465-4467.

Tung, H., Guss, B., Hellman, U., Persson, L., Rubin, K. \& Rydén, C. (2000). A bone sialoprotein-binding protein from Staphylococcus aureus: a member of the staphylococcal Sdr family. Biochem J 345, 611-619.

Vivoni, A. M. \& Moreira, B. M. (2005). Application of molecular techniques in the study of Staphylococcus aureus clonal evolution - a review. Mem Inst Oswaldo Cruz 100, 693-698.

Wagner, L. \& Lai, E. (1994). Separation of large DNA molecules with high voltage pulsed field gel electrophoresis. Electrophoresis 15, 1078-1083.

Wertheim, H. F. L., Melles, D. C., Vos, M. C., van Belkum, A., Verbrugh, H. A. \& Nouwen, J. L. (2005). The role of nasal carriage in Staphylococcus aureus infections. Lancet Infect Dis 5, 751-762.

Wright, J. S., III, Traber, K. E., Corrigan, R., Benson, S. A., Musser, J. M. \& Novick, R. P. (2005). The agr radiation: an early event in the evolution of staphylococci. J Bacteriol 187, 5585-5594. 